\title{
DELITOS CONTRA EL DERECHO DE AUTOR
}

\author{
Eduardo ORÉ SOSA \\ Miembro del instituto de Ciencia Procesal Penal (INCiPP) \\ PROFESOR DE DERECHO PENAL \\ Universidad DE PiURA (PERÚ)
}

SuMARIO: I. Introducción. II. Derecho de autor y derechos conexos. Marco teórico. II.I. Los bienes inmateriales y el derecho de autor. II.2. Obra protegible. II.3. Contenido del derecho de autor. II.3.I. Los derechos morales. II.3.2. Los derechos patrimoniales. II.4 Limitaciones o límites del derecho de explotación. II.5. Derechos conexos. II.5.I. Artista intérprete o ejecutante. II.5.2. Productores de fonogramas. II.5.4. Otros derechos conexos. II.5.3. Organismo de radiodifusión. III. Protección penal. III.I. Bien jurídico protegido. III.2. El ilícito: infracción administrativa vs. delito. III.3. Figuras penales. III.4. Tipos penales incorporados por la Ley $\mathrm{N}^{\circ}$ 29263. III.4.I. Elusión de medidas tecnológicas. III.4.2. Delitos contra la información sobre gestión de derechos. III.4.3. Fabricación y comercialización de etiquetas. III.4.4. Manuales y licencias para programas de ordenador. III.4.5. Protección de señales satelitales. III.5. La incautación y el comiso. IV. Excurso: «El otro sendero». IV.I. Breve referencia de los hechos. IV.2. Sujeto activo del delito: ¿el autor de la obra? IV.3. Coautor de la obra, ¿autor del delito? IV.4. ¿Delito de desobediencia? V. Bibliografía.

RESUMEN: La importancia del derecho de autor es indiscutible. Los delitos incorporados en el Código penal peruano, en esta materia, poco pueden distinguirse de las infracciones administrativas. Asimismo, en la configuración de estos delitos, el legislador parece haber tenido en la mira compromisos comerciales internacionales y, en menor medida, la realidad del fenómeno criminal.

PALABRAS ClAVE: derecho de autor, delito, penas.

\section{CRIMES AGAINST COPYRIGHT}

ABSTRACT: The importance of copyright cannot be denied. It is hard difficult to distinguish the crimes incorporated in the Peruvian criminal code from administrative violations. The legislator seems to give great importance to international trade agreements, but less to the criminal phenomenon.

KEYWORDS: copyright, crime, punishment. 


\section{Introducción}

El Guernica es quizás una de las pinturas más emblemáticas de Picasso. El dolor y la insania en su máxima expresión quedan plasmados en esta obra que debe su nombre a la villa vasca bombardeada por la aviación alemana el 26 de abril de i937. La pintura había sido encargada por el Gobierno de la Segunda República, que sufría los embates de las huestes franquistas apoyadas militarmente por Hitler y Mussolini. Presentada en la Exposición Universal de París (I937), tuvieron que pasar 44 años para que el Guernica regrese a España. La razón: Picasso había dispuesto que la obra solo fuese llevada a su país luego de finalizada la dictadura, pues Franco ya se encontraba en el poder. El cuadro formaba parte del patrimonio cultural del Estado español, cierto, pero la voluntad del artista estaba por encima de ello: el autor es amo y señor de su obra... casi siempre.

Decimos esto porque no siempre es así. Repárese en lo que sucede con las obras arquitectónicas originales (por ejemplo edificios o puentes), que son susceptibles de protección por el derecho de autor: debido a que están destinadas a un fin utilitario (servir de vivienda o tránsito), puede suceder que el derecho del creador (por ejemplo a que no se modifique su obra) ceda ante el interés público de quienes normalmente hacen o pueden hacer uso de ellas (construir puertas o salidas de emergencia; nuevas vías de acceso; rampas para el uso de personas en silla de ruedas, etc.).

El presente artículo pretende hacer un breve análisis de las modalidades típicas incorporadas en el catálogo punitivo peruano con la promulgación de la Ley $\mathrm{N}^{\circ} 29263$. Como se sabe, estas modificaciones tienen como marco el proceso de implementación del Acuerdo de Promoción Comercial Perú-Estados Unidos, más conocido como TLC.

No obstante, a los efectos de tener una visión de conjunto, analizaremos también las demás figuras típicas. Para ello, es necesario abordar antes, siquiera brevemente, algunos conceptos sobre el derecho de autor.

\section{Derecho de autor y derechos conexos. Marco teórico.}

\section{I. Los bienes inmateriales y el derecho de autor}

Podemos dividir los bienes inmateriales en tres grandes grupos: las creaciones industriales, los signos distintivos y las creaciones intelectuales (Gómez Segade 200I, 3I32). Como creaciones industriales podemos señalar, entre otros, las patentes y los modelos de utilidad. Entre los signos distintivos, contamos con las marcas y los nombres comerciales. Y entre las creaciones intelectuales, los derechos de autor y derechos conexos.

El núcleo esencial de los distintos derechos de la Propiedad Intelectual consiste en un derecho de exclusividad que confiere a su titular no sólo la facultad de explotar el bien inmaterial, sino también de impedir que pueda ser utilizado por terceros. Esta suerte de monopolio legal supone un derecho de exclusiva en favor del titular, el mismo que es oponible erga omnes en las condiciones y términos expresados por la Ley.

En cuanto al derecho de autor, puede afirmarse que la tutela de la creación intelectual sirve tanto a los fines de difusión de los valores culturales como a los de fomento del desarrollo tecnológico. De hecho, puede decirse que tan importante como la creación, es la difusión. Parecería poco atractivo consumir mucho talento y esfuerzo en crear algo, para que sean otros los que se aprovechen indebidamente de nuestra obra. De ahí que la ley protege al autor para garantizarle: i) un derecho de cuasi-disposición sobre su obra; y ii) la apropiación del producto económico que pueda obtener de ella. De esto, la protección 
jurídica puede traducirse en dos aspectos fundamentales: el señorío del autor sobre su obra y el goce de los beneficios económicos que su explotación reporta (Baylos I993, 48 y ss).

El Derecho de autor, consecuentemente, está preordenado a la protección de los derechos reconocidos al creador de una obra personal y original. Estos derechos nacen por el mismo acto de creación. Por tanto, el registro de la obra no es constitutivo, aun cuando pueda servir como prueba de anterioridad en caso de plagio.

\section{II.2. Obra protegible}

Una obra es una creación intelectual personal y original. En efecto, estamos ante un bien inmaterial, carente de una existencia sensible per se, y que sólo puede ser percibido en tanto es fijado y reproducido en un soporte material.

Ahora bien, siendo que la obra es objeto de protección por el derecho de autor, también es de resaltar que no toda «obra» o producto del ingenio humano es susceptible de este tipo de protección. Una obra para ser tal -por lo menos a los efectos del Derecho de autor- debe reunir una serie de requisitos. Así, según el artículo 2 inc. I7 del Decreto Legislativo 822 [del Perú] Ley sobre el Derecho de Autor (en adelante: LDA), una obra es «Toda creación intelectual personal y original, susceptible de ser divulgada o reproducida en cualquier forma, conocida o por conocerse». De esto, la obra, como fruto del ingenio y el esfuerzo creativo del hombre, debe ser original.

Ahora bien, la originalidad de una obra no se desvirtúa por el solo hecho de que existan obras anteriores que hayan podido servirle de modelo. En este sentido, no cabe duda de que la pintura del artista colombiano Fernando Botero, al recrear La Monalisa de Leonardo da Vinci, es original. Y lo es porque desde el punto de vista del Derecho de autor, la originalidad debe ser entendida como aquella característica consistente en la individualidad que el autor imprime a su obra, esto es, cuando en ella vuelca la impronta o sello de su personalidad. Por tanto, la originalidad no debe ser confundida con la novedad.

El valor o mérito de una obra son indistintos para que una obra sea susceptible de protección por el derecho de autor. Por lo demás, así lo señala también el primer párrafo del artículo 3 LDA. Y es que la valoración de una obra, sea esta artística o científica, tiene una carga subjetiva tan grande como para hacer depender de ella la protección que deba brindar el Derechor.

También debe tenerse en cuenta que no se protegen las ideas, sino la forma en que se exteriorizan. La razón es sencilla: existe un interés en el libre uso de las ideas, pues ello permite el desarrollo y progreso de la ciencia, el arte y las humanidades. En consecuencia, no se puede establecer un monopolio o un derecho exclusivo sobre ellas.

El artículo 5 LDA contiene un listado enunciativo de las obras que son susceptibles de protección. Entre ellas podemos mencionar las obras literarias, ya sean estas escritas (novelas, cuentos, monografías) u orales (conferencias, clases, alocuciones); las composiciones musicales; las obras audiovisuales (p. ej. una película); las obras de artes plásticas (pinturas, esculturas, dibujos); las obras de arquitectura; las obras fotográficas; los programas de ordenador (software); etc.

\footnotetext{
${ }^{I}$ A este respecto Lipszyc (I993, 67) señala: «Se trata de una cuestión de gustos cuya consideración corresponde al público y a la crítica, no al derecho. Lo contrario podría dar lugar a toda clase de arbitrariedades, en particular en una materia que presenta numerosos ejemplos de grandes obras que en ocasión de ser representadas, ejecutadas o expuestas por primera vez, fueron abucheadas y que, con el correr de los años, lograron un reconocimiento y un prestigio notables...».
} 
Como decíamos, se trata de un listado enunciativo, toda vez que el último literal del artículo en mención contiene una cláusula abierta con el objeto de comprender entre las obras protegidas a «toda otra producción del intelecto en el dominio literario o artístico, que tenga características de originalidad y sea susceptible de ser divulgada o reproducida por cualquier medio o procedimiento, conocido o por conocerse».

\section{II.3. Contenido del derecho de autor}

El derecho de autor comprende dos aspectos: por un lado, los derechos morales, que son perpetuos, inalienables, inembargables, irrenunciables e imprescriptibles (art. 2I LDA); $\mathrm{y}$, por otro, los derechos patrimoniales, que, a diferencia de los anteriores, sí tienen un plazo de vigencia (toda la vida del autor y setenta años después de su fallecimiento: art. 52 LDA), transcurrido el cual, la obra pasa al dominio público.

Cabe mencionar que algunos países — principalmente Estados Unidos y otros que adscriben al sistema del copyright- se muestran más sensibles a las infracciones de los derechos patrimoniales de autor y derechos conexos, que a ilícitos que inciden en el aspecto moral.

\section{II.3.I. Los derechos morales}

Según el art. 22 LDA son derechos morales el derecho de divulgación, el derecho de paternidad, el derecho de integridad, el derecho de modificación o variación, el derecho de retiro de la obra del comercio y el derecho de acceso.

En cuanto al primero de estos derechos, se tiene que sólo al autor corresponde decidir si su obra será divulgada, esto es, puesta en conocimiento del público y en qué forma (p. ej. por fascículos o entregas). Y si sólo al autor corresponde la decisión de dar a conocer su obra, también tiene el correlativo derecho de mantenerla inédita o reservada en la esfera de su intimidad (Lipszyc I993, I05).

Por el derecho de paternidad, según el art. 24 LDA, el autor tiene el derecho de ser reconocido como tal, es decir, a reivindicar la obra como suya. De este modo, el autor tiene el derecho a que el fruto de su creación lleve su nombre, o que la divulgación de su obra, si así lo considera conveniente, se haga bajo seudónimo, signo o de manera anónima.

Por el derecho de integridad se reconoce al autor la facultad de oponerse a cualquier modificación o mutilación de la obra. Este derecho es oponible incluso a quien haya adquirido el objeto material que contiene la obra (art. 25 LDA). Como señala Lipszyc (I993, I68), «El autor tiene derecho a que su pensamiento no sea modificado o desnaturalizado, y la comunidad tiene derecho a que los productos de la actividad intelectual creativa le lleguen en su auténtica expresión».

El autor también ostenta el derecho de modificar su obra, antes o después de su divulgación. Lo que es muy usual en las obras literarias de carácter científico (p. ej. manuales de Derecho), en las que se procede a correcciones, ampliaciones o cambios de postura en las ediciones posteriores de las mismas.

El autor goza asimismo del derecho de retirar su obra del comercio, generalmente por un cambio en sus convicciones. Puede ocurrir que el autor llegue a repudiar su obra, como ocurriría por ejemplo, si el autor de una novela anticlerical se convierte 
posteriormente al catolicismo. Este derecho no comprende el retiro de las obras que estén fuera de los canales de distribución comercial (bibliotecas, usuario final, etc.).

Atendiendo al art. 28 LDA, el autor tiene la facultad de acceder al ejemplar único o raro de la obra cuando se halle en poder de otro a fin de ejercitar sus demás derechos morales o patrimoniales reconocidos por la ley. Es que una cosa es ser propietario del objeto donde se manifiesta la obra (quien compra una escultura o pintura), y otra distinta el ostentar la titularidad de los derechos morales y patrimoniales sobre la misma. Como ya dijimos, los derechos morales son inalienables e irrenunciables. Y en el aspecto patrimonial, es el autor quien goza del derecho exclusivo de explotar su obra, ya sea personalmente o a través de terceros. Con lo cual, quien adquiere una pintura no tiene, por ese solo hecho, la facultad de modificar la obra o ejercer actos de explotación. Estos derechos permanecen en el autor, y es por ello que esta disposición garantiza el derecho de acceso, justamente para que el creador de la obra pueda ejercer sus derechos morales o patrimoniales.

\section{II.3.2. Los derechos patrimoniales}

Los derechos patrimoniales reconocidos al autor están preordenados a garantizarle el disfrute de los beneficios económicos obtenidos por la explotación de su obra. El art. 3I LDA contiene un listado enunciativo de los derechos de contenido patrimonial, pudiéndose apreciar un doble aspecto. El primero, consistente en el derecho que tiene el autor de utilizar su obra por sí o a través de terceros, para lo cual el legislador utiliza la expresión «el derecho exclusivo de realizar, autorizar...». El segundo aspecto reconoce al autor el derecho de prohibir el uso o explotación de su obra por terceros que no cuenten con su autorización o consentimiento (ius prohibendi).

Específicamente, el autor podrá realizar, autorizar o prohibir la reproducción de la obra; la comunicación pública; la distribución al público; la traducción, adaptación y otras formas de transformación; la importación de copias hechas sin autorización; y cualquier otra forma de utilización no prevista como excepción

La reproducción supone la fijación de la obra o producción intelectual en un soporte o medio que permita su comunicación, incluyendo su almacenamiento electrónico y la obtención de copias de todo o parte de ella (art. 2 inc. 37 LDA). Ello comprende la obtención de ejemplares por medio de la imprenta; la fijación y reproducción de obras sonoras o audiovisuales en soportes digitales; el almacenamiento de programas en un computador, etc.

La comunicación pública es todo acto por el cual una o más personas, reunidas o no en un mismo lugar, pueden tener acceso a la obra sin previa distribución de ejemplares a cada una de ellas, por cualquier medio o procedimiento, análogo o digital (art. 2 inc. 5 LDA). Es el caso de la exhibición de una obra de arte en una galería; la puesta en escena de una obra de teatro; la proyección de películas en salas cinematográficas; la comunicación a distancia por medio de la radio o televisión.

Según el art. 34 LDA, la distribución comprende la puesta a disposición del público, por cualquier medio o procedimiento, del original o copias de la obra, por medio de la venta, canje, permuta $u$ otra forma de transmisión de la propiedad, alquiler, préstamo público o cualquier otra modalidad de uso o explotación. No obstante, es de aclarar que respecto de las obras ya divulgadas lícitamente, es permitida sin autorización del autor el préstamo al público del ejemplar lícito de una obra expresada por escrito, por una biblioteca o archivo cuyas actividades no tengan directa o indirectamente fines de lucro (art. 43 lit. «f» LDA). 
Al autor también le corresponde el derecho de autorizar o prohibir la traducción, adaptación, arreglo u otra forma de transformación de la obra, lo que da lugar a una obra derivada. Es derivada en tanto está basada en otra ya existente (obra originaria), tal como lo señala el art. 2 inc. 25 LDA.

En cuanto a la importación de copias hechas sin autorización, es de apreciar el mayor ámbito de aplicación que la LDA concede al término importar con relación al previsto en el derecho de marcas. En este último la importación alude a la introducción en territorio nacional de objetos fabricados en el extranjero por cualquier medio terrestre, aéreo o marítimo (Oré 2007, II8). Cuando del derecho de autor se trata, en cambio, la importación incluye la transmisión, analógica o digital, de copias de la obra.

\section{II.4. Limitaciones o límites del derecho de explotación}

Si los derechos morales admiten ciertos límites², con mayor razón los derechos de explotación están sujetos a determinadas limitaciones o excepciones. Con esto se alude a la existencia de actos que entrañan un uso o aprovechamiento no autorizado de la obra que no pueden ser prohibidos, esto es, que deben ser tolerados por el autor o por quien ostente la titularidad de los derechos de explotación de la obra.

En este sentido, el art. 4I LDA enumera una serie de actos de comunicación cuando una o más personas tienen o pueden tener acceso a la obra sin previa distribución de ejemplares - que no requieren autorización del autor, ni están sujetos al pago de remuneración alguna: cuando se realicen en un ámbito exclusivamente doméstico; las efectuadas en el curso de actos oficiales o ceremonias religiosas; las verificadas con fines exclusivamente didácticos, en el curso de las actividades de una institución de enseñanza. En estos tres casos, la comunicación no deberá perseguir o traducir un fin lucrativo o interés económico. Asimismo, están permitidos los actos de comunicación realizados dentro de los establecimientos comerciales que tengan un fin demostrativo de equipos de sonido o para la venta de soportes sonoros o audiovisuales.

El art. 43 LDA contiene diversos supuestos de reproducción lícita sin autorización del autor: la reproducción de artículos o breves extractos de obras que se realicen para la enseñanza o realización de exámenes en instituciones educativas, siempre que no haya fines de lucro y se haga conforme a los usos honrados; la reproducción por reprografía (p. ej. fotocopias) de breves fragmentos o de obras agotadas para uso exclusivamente personal; la reproducción de obras, con fines de conservación o sustitución, que tengan por fin preservar los ejemplares de bibliotecas o archivos públicos; la reproducción de una obra para actuaciones judiciales o administrativas; la reproducción de una obra de arte expuesta permanentemente en espacios abiertos (calles, plazas, fachada exterior de edificios) por medio de un arte diverso al empleado para la elaboración del original; los préstamos efectuados por bibliotecas o archivos; la reproducción de obras de ingenio para uso privado de invidentes efectuadas en sistema Braille $u$ otro procedimiento específico.

Igualmente, el art. 45 LDA establece como límites del derecho de explotación: la difusión con fines informativos de imágenes o sonidos de obras vistas u oídas en acontecimientos de actualidad (p. ej. conciertos, exposición de obras de arte); la difusión de los discursos, disertaciones, alocuciones sermones y obras similares que, a título informativo, sean difundidos por la prensa; la emisión por radiodifusión, por cable o

${ }^{2}$ Sólo a modo de ejemplo: el derecho del autor a que su obra se mantenga en forma anónima, que no podrá extenderse cuando haya caído en el dominio público (art. 23 LDA); el derecho de retiro de la obra del comercio, que se extingue a la muerte del autor, a diferencia de otros derechos morales que perduran incluso setenta años después de la muerte (art. 27 LDA).. 
cualquier otro medio de la imagen de una obra arquitectónica, plástica, de fotografía o de arte aplicado, que se encuentren situadas permanentemente en un lugar abierto al público.

\section{II.5. Derechos conexos}

Los derechos conexos no protegen obras, al menos en el sentido del Derecho de autor. Pero sí protegen las interpretaciones o ejecuciones artísticas; los derechos de los productores de fonogramas; los derechos de los organismos de radiodifusión sobre sus emisiones, etc. Como dice Rangel (I998, II5), «existen trabajos de naturaleza intelectual que aun cuando no pueden considerarse una creación en sentido estricto, se asimilan a ella por revelar un esfuerzo de talento que les imprime una individualidad derivada ya sea del conocimiento científico, de la sensibilidad o de la apreciación artística de quien los realiza». En caso de conflicto entre estos derechos y los del autor, priman los de este último.

\section{II.5.I. Artista intérprete o ejecutante}

Se define como la «Persona que representa, canta, lee, recita, interpreta o ejecuta en cualquier forma una obra literaria o artística o una expresión del folklore, así como el artista de variedades y de circo» (art. 2 inc. 2 LDA). De conformidad con los arts. I3I a I35 LDA, gozan de algunos derechos morales (el reconocimiento de su nombre sobre sus interpretaciones y la oposición a cualquier modificación o mutilación de sus actuaciones que lesione su prestigio o reputación) y patrimoniales (explotación de sus interpretaciones o ejecuciones mediante actos de comunicación al público o reproducción; a percibir una remuneración por la comunicación pública de los fonogramas que contenga la interpretación o ejecución, etc.). La duración de la protección se extenderá a toda la vida del artista y setenta años después de su fallecimiento.

\section{II.5.2. Productores de fonogramas}

Por fonograma se entiende, según el art. 2 inc. I4 LDA, «Los sonidos de una ejecución o de otros sonidos, o de representaciones digitales de los mismos, fijados por primera vez, en forma exclusivamente sonora. Las grabaciones gramofónicas, magnetofónicas y digitales son copias de fonogramas». También se les reconoce derechos patrimoniales, ya que tienen el derecho de uso exclusivo de sus fonogramas, con lo cual, pueden realizar, autorizar o prohibir la reproducción directa o indirecta de sus fonogramas, su distribución al público, su inclusión en obras audiovisuales, etc. (art. 136 LDA). Asimismo tienen derecho a percibir una remuneración por la comunicación de sus fonogramas al público (art. I37 LDA), como es el caso de bares, discotecas, locales abiertos al público, etc. La protección es de setenta años, contados a partir del primero de enero del año siguiente a la primera publicación del fonograma, transcurridos los cuales, el fonograma pasará a dominio público (art. I39 LDA).

\section{II.5.3 Organismo de radiodifusión}

Según el art. 2 inc. 30 LDA, el organismo de radiodifusión es «La persona natural o jurídica que decide las emisiones y que determina el programa así como el día y la hora de la emisión». Por emisión, en tanto, se entiende la difusión a distancia directa o indirecta de sonidos, imágenes, o de ambos, para su recepción por el público, por cualquier medio o procedimiento (art. 2 inc. II LDA). Los organismos de radiodifusión tienen el derecho de realizar, autorizar o prohibir la retransmisión, grabación o reproducción de sus emisiones, 
así como a obtener una remuneración por la comunicación pública de sus emisiones o transmisiones de radiodifusión, cuando se efectúe en lugares a los que el público acceda mediante pago de un derecho de admisión o entrada (art. I40 LDA).

\section{II.5.4 Otros derechos conexos}

Grabaciones de imágenes con o sin sonido que no sean creaciones susceptibles de ser calificadas como obras audiovisuales; fotografía $u$ otra fijación obtenida por un procedimiento análogo que no reúna los requisitos necesarios para ser considera una obra; quien publique por primera vez una obra inédita que esté en el dominio público. En estos casos, el ámbito de protección que concede la ley — tanto por el contenido como por el plazo- es menor (arts. I43 a I45 LDA).

\section{Protección penal}

\section{III.I. Bien jurídico protegido}

El bien jurídico protegido en las figuras penales ahora analizadas es el derecho de autor y, en algunos casos, los derechos conexos. La protección penal se encamina a perseguir aquellos comportamientos que supongan una vulneración tanto de las facultades morales como patrimoniales, con cierta preeminencia de estas últimas. En efecto, si bien se reprimen conductas que suponen la afectación de derechos morales tales como el derecho a la paternidad, a la integridad y a la no divulgación de la obra, lo cierto es que buena parte de los comportamientos delictivos — con más razón desde la entrada en vigor de la Ley 29263 que incorpora nuevas figuras típicas - tienen que ver con actos de comunicación, distribución, reproducción e importación atentatorios contra las facultades patrimoniales de los derechos de autor y conexos.

Parece claro que algunos países — principalmente Estados Unidos- se muestran más sensibles a las infracciones a los derechos patrimoniales de autor y derechos conexos que a ilícitos que inciden en el aspecto moral. Aquéllos son los que generan mayor preocupación en los países que han alcanzado un gran desarrollo de sus industrias fonográfica, audiovisual, satelital y del software. Estamos ante intangibles que generan grandes ganancias.

Debe tenerse en cuenta que entre los derechos de autor (que atiende en sentido estricto a los creadores) y los derechos conexos (esto es, de los intérpretes o ejecutantes; de los productores de fonograma, y de los organismos de radiodifusión) se pueden establecer vasos comunicantes:

«Lo que se observa sin mayor esfuerzo es que las obras de los autores son el insumo o la materia prima de la cual se valen los titulares de los denominados derechos conexos o vecinos, y a su vez los autores encuentran en los titulares de derechos conexos sus mejores aliados en la labor de dar a conocer y de difusión de sus creaciones, lo cual crea una especie de matrimonio por conveniencia entre unos y otros» (Ríos 2003, 47). 
III.2. El ilícito: infracción administrativa vs. delito

Es de notar cierta yuxtaposición entre el ilícito penal y el ilícito administrativo. Lo que parece difícil de evitar si se tiene en cuenta que estamos ante dos sistemas de protección, pero con un único objeto de tutela. Más aún cuando el art. I83 LDA prescribe: «Se considera infracción la vulneración de cualquiera de las disposiciones contenidas en la presente ley».

Resulta difícil fundamentar las diferencias materiales en cuanto al contenido del delito y del ilícito administrativo, si se compara el segundo párrafo del art. I86 LDA con algunas conductas previstas por el legislador en el catálogo punitivo: vulneración de derechos morales [arts. 216, 2I8 a) y 2I9 CP]; presentación de declaraciones falsas en cuanto a certificaciones de ingresos, repertorio utilizado, número de ejemplares producidos [art. 220 c) CP]; realización de actividades propias de una entidad de gestión colectiva sin contar con la respectiva autorización de la Oficina de Derecho de Autor [art. 220 b) CP].

Queda la impresión de que el legislador no parece preocuparse de la mayor dañosidad que debe comportar un delito con relación a la mera infracción administrativa, esto es, al mayor grado de injusto. Lo que en el caso concreto puede generar dificultades para determinar si estamos o no ante un comportamiento punible.

\section{III.3. Figuras penales}

En el art. 2I6 CP (copia o reproducción no autorizada), el legislador recoge una serie de modalidades que tienen en común que el agente cuenta con la autorización -ya sea del autor o del titular del derecho- para la publicación de la obra. Como veremos posteriormente, este hecho nos lleva a plantear que estos supuestos sean regulados en la vía civil o administrativa, mas no en vía penal.

Las conductas previstas atentan contra los derechos de paternidad (omitir el nombre del autor o estampar su nombre con adiciones o supresiones), de integridad (modificar la obra) y divulgación (publicar la obra-separada o conjuntamente- de manera contraria a la especificada por el autor).

Asimismo, es de tener en cuenta que el objeto de protección no solo está constituido por la obra originaria, sino también por las obras derivadas (traducción, adaptación, arreglos y compilaciones).

En el art. 2I7 CP (reproducción, difusión, distribución y circulación de la obra sin la autorización del autor), se protege tanto el derecho de autor (con respecto a una obra), como los derechos conexos (sobre una interpretación, ejecución, fonograma; sobre una emisión o transmisión de radiodifusión; o con relación a una grabación audiovisual o a una imagen fotográfica).

Las conductas típicas tienen que ver con afectaciones tanto a los derechos morales (no modificación), como a los patrimoniales (distribución, comunicación, reproducción, etc.). Estas conductas se realizan sin la debida autorización del titular del derecho (de autor o conexo), salvo el supuesto previsto en el literal «d», en el que hay autorización, pero la reproducción, comunicación o distribución se hace en mayor número al autorizado.

Sin embargo, es curioso que la reproducción sin autorización no se mencione como tipo básico -como sí se hace en el mismo artículo (literales «b» $\mathrm{y}$ «c») con respecto a los actos de distribución y comunicación pública-, mas sí como uno agravado. En efecto, en 
el último párrafo se sanciona con un marco penal mayor la reproducción total o parcial por cualquier medio o procedimiento. Claro que podríamos preguntarnos si el último párrafo contiene dos supuestos agravados (la reproducción total o parcial, por un lado, y la distribución mediante venta, alquiler o préstamo público que supere las 2 UIT, por otro) o uno solo (el agente tiene que reproducir y, a la vez, distribuir). Lo más coherente parecería optar por lo primero, pues, de lo contrario, los actos no autorizados de reproducción de la obra, sin que medie distribución, sólo podrían quedar reprimidos a título de tentativa.

En cualquier caso, consideramos que los actos de reproducción, distribución y comunicación en mayor número que el autorizado debería constituir una infracción a ser solventada con arreglo a las normas civiles y administrativas.

El artículo 2I8 regula lo que el legislador considera formas agravadas. En el literal «a» (dar a conocer al público una obra inédita) el mayor desvalor del injusto se hace reposar en la vulneración del derecho moral de divulgación de la obra. Ya habíamos dicho que al autor le corresponde decidir si su obra será divulgada, es decir, puesta en conocimiento del público. Consecuentemente, también tiene el derecho de mantenerla inédita.

En el literal «b» cuestionamos la consideración de los fines comerciales $u$ otro tipo de ventaja económica como factores agravantes, pues ellas constituyen elementos de tendencia interna trascendente generalmente presentes en los delitos contra el derecho de autor. También se comprende en este literal la alteración o supresión del nombre o seudónimo del autor, actos que constituyen vulneraciones del derecho de paternidad de la obra. La omisión del nombre del autor y su sustitución por el de un tercero también afecta el derecho de paternidad, pero se subsumiría, más bien, en el delito de plagio.

En el literal «c» se incluyen actos de distribución, almacenamiento y ocultamiento de ejemplares de origen ilícito, así como su ingreso y salida del país. Parecería que la conducta de almacenar ya comprende la de ocultar, más aún si hablamos de copias o ejemplares de origen ilícito. No obstante, una verdadera confusión genera el hecho de que se incluya nuevamente, esta vez bajo una forma agravada, la acción de distribuir las copias al público por cualquier medio.

La distribución de ejemplares ya está regulada en el art. 2I7 CP. No parece apropiado señalar que el legislador se refiere, en el art. 2I8 CP, al supuesto en que el agente distribuye lo que ha sido reproducido por otro -aunque esta interpretación sea correcta desde el punto de vista literal: «conociendo el origen ilícito de la copia o reproducción»-, mientras que en el artículo anterior se reprime al que reproduce y a la vez distribuye. No parecería razonable sancionar con más pena al que hace menos. Seguramente el legislador ha querido sancionar más severamente actos de receptación (en el art. I94 CP la receptación se sanciona con pena privativa de libertad no menor de uno ni mayor de tres años y con treinta a noventa días-multa), pero lo hace al costo de que cualquier acto de distribución casi siempre podrá ser reconducido directamente a la forma agravada.

La modalidad prevista en el literal «d» guarda estrecha relación con lo regulado en los artículos 220-A, 220-B y 220-C incorporados por la Ley 29263. Se trata de la fabricación o comercialización de dispositivos destinados a sortear aquellos mecanismos empleados para la protección de derechos de autor (los que buscan evitar las copias o reproducciones, los que establecen códigos de acceso, etc.). La elusión de estas medidas tecnológicas aparecería como una anticipación de las barreras de protección del bien jurídico, pues con dichas conductas -las que sortean estos dispositivos-, se abre justamente la posibilidad de realizar actos que vulneran los derechos de autor: actos de reproducción, uso no autorizado, etc.

Con relación al supuesto previsto en el literal «e» (inscribir en el Registro del Derecho de Autor una obra ajena) debe precisarse que el derecho de autor sobre una obra 
no nace en virtud del registro, sino por el mismo acto de creación. De esto, como ya fue mencionado, el registro no es constitutivo del derecho. De ahí que por autor de una obra se tendrá siempre al creador, mas no al que indebidamente usurpa dicha condición a través del registro -como si fuera propio- de una obra ajena. Dicha conducta bien podría subsumirse en un delito contra la fe pública (falsedad ideológica), aunque el legislador ha preferido incluirla -con un marco penal más grave- como una forma agravada de los delitos contra el derecho de autor.

El delito de plagio queda regulado en el art. 219. En el plagio se vulnera de lleno el derecho moral de paternidad de la obra, pues se pretende pasar como propia una creación ajena. Esto implica actos de reproducción o cuasi reproducción de la obra (copia servil) o actos en los que se busca disimular el plagio incorporando ciertas alteraciones (copia inteligente).

Si las ideas no pueden ser objeto de apropiación ni de un derecho de exclusiva vía derecho de autor, entonces tomar una idea ajena no podrá ser considerado como un plagio.

Que el legislador admita la posibilidad de que el agente atribuya a otro la autoría sobre una obra ajena, no supone que conceda relevancia penal al plagio inverso. Según Latorre (I994, 202), «Esta modalidad de plagio que no es tal, consiste en atribuir una obra a un autor que no la ha creado para aprovecharse de su fama y mérito»³. En este caso no se violaría el derecho de paternidad de quien, al fin y al cabo, no ha sido creador de la obra que indebidamente se le atribuye. Otra cosa es que dichos comportamientos puedan subsumirse en otras figuras penales como la estafa o la falsedad genérica.

En el art. 220 se incluye, inexplicablemente, otras formas agravadas. En el literal «a», el legislador desvalora aún más el comportamiento de aquel que impide -usurpando la calidad de titular del derecho- actos legítimos de comunicación, reproducción o distribución. El mayor contenido de injusto se encuentra, además, en que se induce a error a la autoridad.

El literal «b» incorpora como modalidad agravada el realizar actividades propias de una entidad de gestión colectiva sin contar con la debida autorización administrativa. Las sociedades de gestión colectiva son asociaciones civiles sin fines de lucro legalmente constituidas para dedicarse, en nombre propio o ajeno, a la gestión de derechos de autor o conexos, sobre todo derechos de carácter patrimonial. Para ello deben contar con la autorización de la Oficina de Derechos de Autor del Indecopi. En este sentido, aquel que conceda autorizaciones para la explotación de las obras, o fije y recaude la remuneración correspondiente a dicha explotación incurrirá en este delito en su forma agravada si es que no cuenta con la debida autorización. Si bien es verdad que la distribución -a los titulares de un derecho de autor o conexo- de las remuneraciones recaudadas constituye una función de las sociedades de gestión, hacerlo efectivamente, aun sin contar con la autorización debida, no parecería afectar los intereses de los autores, compositores o intérpretes, sino todo lo contrario. A pesar de ello, también queda comprendida como una forma agravada. Y es que estas entidades conservan una parte de la remuneración por concepto de gastos administrativos $(30 \%)$ y gastos socioculturales $(10 \%)^{4}$, lo que solamente puede admitirse en favor de entidades que hayan sido reconocidas como sociedades de gestión colectiva por la autoridad administrativa correspondiente.

Es de entender que estas entidades se constituyen para una mejor gestión de los derechos de autor y conexos. No obstante, puede suceder que los responsables de estas entidades realicen determinadas conductas que vayan en perjuicio de los derechos administrados. Estas son justamente las que se mencionan en el literal «c» del presente

\footnotetext{
${ }^{3}$ Se trata de un supuesto, como señala Lipszyc (I993, I67-I68) de falsa atribución de paternidad.

${ }^{4}$ Cfr. art. I53 lit. j) LDA.
} 
artículo. Se trata de conductas defraudatorias que atentan contra los intereses patrimoniales de los titulares de los derechos de autor o conexos representados por la entidad.

La circunstancia agravante prevista en el literal «d», consistente en la pertenencia a una organización destinada a perpetrar estos ilícitos, nos parece innecesaria, pues basta aplicar la regla del concurso de delitos (con el de pertenencia a organización criminal: art. 3I7 CP) para determinar la pena acorde al grado de injusto. Por si fuera poco, es de tener en cuenta que la gran mayoría de los casos podrán ser reconducidos a la forma agravada, pues es raro que estos ilícitos sean perpetrados de manera individual o sin un mínimo organizativo.

La circunstancia del literal «e» se atiene a la condición de funcionario o servidor público del agente. En otro lugar ya hemos cuestionado esta agravante (Oré 2007, I75-I77). Sólo por mencionar algunos de los cuestionamientos, debe repararse en que ya contamos con el artículo 46-A del Código Penal, que podría eventualmente aplicarse al caso propuesto (más allá de la crítica que quepa hacer a este artículo). Siendo además, que el literal «d» del artículo 220 fundamenta la agravante en la sola condición de funcionario o servidor público, sin que se exija algún tipo de aprovechamiento de su condición o cargo para la perpetración del hecho punible. Esto es más propio de un derecho penal de autor, lo que resulta francamente inadmisible.

\section{III.4. Tipos penales incorporados por la Ley N²9263}

Como ya se adelantó, las modificaciones efectuadas al CP han venido de la mano de las obligaciones asumidas por el Estado peruano a propósito del Acuerdo de Promoción Comercial Perú - Estados Unidos (APC), cuyo capítulo I6 está referido justamente a la Propiedad Intelectual5. Toca ahora analizar los tipos penales incorporados.

\section{III.4.I. Elusión de medidas tecnológicas}

En primer lugar, se tipifican penalmente figuras que suponen la elusión de medidas tecnológicas, es decir, de mecanismos técnicos o informáticos dispuestos por los titulares de un derecho de propiedad intelectual para la evitación o neutralización de actos de infracción por terceros.

Desde hace buen tiempo, la falsificación y piratería han venido exigiendo de los empresarios la búsqueda de mecanismos o dispositivos de seguridad que alertasen al público sobre la autenticidad o no de los productos puestos en el mercado. Más allá del tradicional precinto de seguridad, se ha llegado a utilizar hologramas, tintas fotocromáticas, dispositivos electrónicos y otros. No obstante, como bien señala Rodríguez Gómez (I996, 344), estos dispositivos presentan algunos problemas: no todos los tipos de productos pueden ser protegidos e identificados por estos métodos; los costes añadidos de tales medidas de seguridad no se justificarían para productos de bajo coste; y, por último, se trataría de medidas a corto plazo, pues los falsificadores pronto tendrían a su disposición medios más sofisticados y rápidos para vulnerar dichas medidas. Por lo demás, debe tenerse en cuenta que muchos de estos dispositivos sirven para facilitar la tarea de diferenciar un producto auténtico de uno falso, con lo cual, poco se puede hacer en aquellos casos en el que el propio consumidor está dispuesto a comprar un producto con pleno conocimiento de que se trata de un producto falsificado.

${ }^{5}$ En el marco de la implementación del APC Perú-EEUU, y siempre en lo relacionado al derecho de autor, también se promulgó el Dec. Leg. I076 que modificó algunas disposiciones del Dec. Leg. 822. 
Como se ve, la búsqueda de dispositivos que eviten o dificulten la vulneración de derechos de Propiedad Intelectual es una constante. Siendo así, algunos países «se han visto en la necesidad» de incorporar en sus legislaciones normas que reprimen la fabricación y distribución de instrumentos o equipos específicamente destinados a suprimir o neutralizar dispositivos técnicos o tecnológicos de seguridad. Así por ejemplo se tiene la Directiva 2001/29/CEE del Parlamento Europeo y del Consejo de 22 de mayo, relativa a la armonización de determinados aspectos de los derechos de autor y derechos afines a los derechos de autor en la sociedad de la información, a partir de la cual los Estados miembros de la Unión Europea han venido incorporando en sus legislaciones normas similares a las que venimos comentando.

La Ley 29263 incorpora en el Código Penal estas figuras delictivas. Se reprime tanto la elusión de medidas tecnológicas con fines de comercialización (art. 220-A), cuanto la fabricación, importación o distribución con fines de comercialización de productos destinados a la elusión de medidas tecnológicas (art. 220-B). Asimismo, se tipifica la prestación de servicios para eludir dichas medidas (art. 220-C).

Las «medidas tecnológicas» vienen a constituir un elemento normativo del tipo, el mismo que es definido en el art. 2.5 I de la Ley sobre el derecho de autor. Ahí se consigna que medida tecnológica efectiva significa cualquier tecnología, dispositivo o componente que, en el curso normal de su operación, controla el acceso legal a una obra, interpretación o ejecución o fonograma, o que protege cualquier derecho de autor o conexo. La Directiva 2001/29/CEE entra en más detalle, y define las medidas tecnológicas como «toda técnica, dispositivo o componente que, en su funcionamiento normal, esté destinado a impedir o restringir actos referidos a obras o prestaciones protegidas que no cuenten con la autorización del titular de los derechos de autor o de los derechos afines a los derechos de autor establecidos por ley o el derecho sui generis previsto en el Capítulo III de la Directiva 96/9/CE. Las medidas tecnológicas se considerarán 'eficaces' cuando el uso de la obra o prestación protegidas esté controlado por los titulares de los derechos mediante la aplicación de un control de acceso o un procedimiento de protección, por ejemplo, codificación, aleatorización u otra transformación de la obra o prestación o un mecanismo de control del copiado, que logre este objetivo de protección».

Lo anterior nos merece algunos comentarios.

i) Si el bien jurídico protegido es el derecho de autor, la tipificación de conductas que eluden o neutralizan dispositivos de seguridad de las mismas, en especial las que suponen la fabricación y comercialización de productos destinados a esos ilícitos fines, supone un adelantamiento de las barreras de protección del bien jurídico. Como dice Miró Llinares (2005, I59), se sancionan actos preparatorios para el posterior ataque a los derechos de propiedad intelectual. El adelantamiento de las barreras de protección para crear condiciones de aseguramiento del bien jurídico protegido es, ciertamente, una opción político criminal, pero que debe ser utilizada de manera racional ${ }^{6}$.

ii) Se aprecia la concurrencia de tipos mixtos alternativos que, en algunos casos y como acabamos de señalar, muestran conductas con distintos grados de desarrollo del iter criminis. De esta suerte, así como no puede concurrir en un mismo hecho la tentativa con un delito consumado, tampoco podrían concurrir dos figuras que están dirigidas -aunque en distinta proximidad- a la afectación del mismo bien jurídico. Salvo las particularidades

\footnotetext{
${ }^{6}$ Así, Rojas Vargas (I997, I39) señala: «la punición de determinados actos preparatorios radica en estimaciones político-criminales centradas fundamentalmente en la consideración de que existe un peligro potencial implícito en estos actos para la seguridad de los bienes jurídicos, los que en razón de su alta significancia penal y características propias los hacen merecedores de tutela previa a la ejecución de los delitos a lo que tienden tales aprestamientos humanos, produciéndose entonces una extensión de tipicidad legalmente establecida, que en la mayoría de códigos penales se dirigen principalmente a los delitos político sociales y que en otros va más allá abarcando una protección generalizada de los bienes jurídicos y de la vigencia de la norma».
} 
del caso concreto, claro está (p. ej. distintos autores, siendo que a uno se le impute conductas posesorias y al otro actos de comercialización).

iii) El elemento del tipo penal no es «cualquier medida tecnológica», como podría aparecer de una simple lectura de las figuras penales recientemente incorporadas por el legislador. Debe tratarse de una medida tecnológica efectiva, es decir, medidas específicamente destinadas a controlar o bloquear el acceso -a la obra protegida- a terceros que no cuentan con la autorización del titular. Podría entenderse comprendido en este supuesto aquellos mecanismos previstos para impedir los usos no autorizados en el ámbito de internet, televisión satelital o por cable (Matiz 2002, I2). Sin embargo, es de notar que esta conducta también puede quedar abarcada por el art. 2I 8 d) del CP que se refiere a dispositivos o equipos capaces de permitir o fomentar la recepción de un programa codificado, radiodifundido o comunicado en otra forma al público. Lo curioso es que en esta última disposición la pena va de cuatro a ocho años de pena privativa de libertad, mientras que en el tipo penal previsto en el art. 220-D la pena será no mayor a los dos años de pena privativa de la libertad. Tal parece que el apresuramiento con que fue aprobada y promulgada la Ley 29263 ha impedido una reestructuración sistemática de estos delitos.

iv) A la referencia del legislador en cuanto a que el agente debe actuar con fines de comercialización7, hay que añadir el listado del art. I96 B de la Ley sobre el derecho de autor. Estos actuarían como elementos de exclusión típica (aunque otros los consideran causas de justificación).

III.4.2. Delitos contra la información sobre gestión de derechos

En cuanto al delito previsto en el art. 220-D, se reprime la supresión o alteración de cualquier información sobre gestión de derechos. La información sobre gestión de derechos debe diferenciarse de lo que constituye el objeto de las Sociedades de Gestión Colectiva. Estas son asociaciones civiles sin fines de lucro que se constituyen para defender los derechos patrimoniales reconocidos al titular de un derecho de autor o conexo. En cambio, la información sobre gestión de derechos significa, según el APC (art. i6.7.5.c) y el art. 2.50 de la Ley sobre el derecho de autor: la información que identifica la obra, interpretación o ejecución o fonograma; al autor de la obra, al artista intérprete o ejecutante de la interpretación o ejecución, o al productor del fonograma, o al titular de cualquier derecho sobre la obra, interpretación o ejecución o fonograma; información sobre los términos y condiciones de utilización de las obras, interpretaciones o ejecuciones o fonogramas; cualquier número o código que represente dicha información. Todo esto, «cuando cualquiera de estos elementos estén adjuntos a un ejemplar de la obra, interpretación o ejecución o fonograma».

Esto último resulta importante, pues permite apreciar qué fue lo que nuestro legislador pretendió al estructurar el segundo párrafo del artículo 220-D: «La misma pena será impuesta al que distribuya o importe para su distribución información sobre gestión de derechos, a sabiendas que esta ha sido suprimida o alterada sin autorización; o distribuya, importe para su distribución, transmita, comunique o ponga a disposición del público copias de las obras, interpretaciones o ejecuciones o fonogramas, a sabiendas que la información sobre gestión de derechos ha sido suprimida o alterada sin autorización».

En buena cuenta, lo que se quiere reprimir en el art. 220-D son conductas de adulteración de la información sobre gestión de derechos (primer párrafo) y de importación o distribución de copias de las obras con la información adulterada (segundo párrafo). Y es que puede sonar extraño aquello de «importe... información sobre gestión de derechos»,

\footnotetext{
${ }^{7}$ Sobre este punto, hay consenso en la futilidad de la inclusión de los fines comerciales en estos delitos, pues esta circunstancia no agrega nada al tipo, es obvia e innecesaria (Oré 2006, 284).
} 
pues la información no es algo que se pueda importar. Lo que se puede importar, y eso es lo que se sanciona penalmente, son los ejemplares en los que se haya suprimido o alterado información sobre gestión de derechos, p. ej. el nombre del autor.

Estimamos que la supresión o alteración de cualquier información sobre gestión de derechos (art. 220-D) constituye un distinto supuesto al previsto en el art. 216 a) del CP, pues en éste un elemento del tipo es el contar con autorización para publicar la obra. Más problemas parece generar la comparación del artículo ahora analizado con el art. 2I9 CP. En el delito de plagio se atenta principalmente contra el componente moral o personal del derecho de autor, en especial, el derecho a la paternidad de la obra. No obstante, sería erróneo señalar que a esta figura penal poco le interesa la infracción del derecho de autor en su aspecto patrimonial, pues el legislador mismo alude en el tipo objetivo a la difusión («la difunda como propia»), lo que constituye propiamente un acto de comunicación al público, y que está comprendido dentro de los derechos patrimoniales del derecho de autor. Con todo, creemos que cuando en el caso concreto se aprecie un claro desconocimiento al derecho de paternidad de la obra (consignar en el ejemplar un nombre distinto al que corresponde a su autor vs. la mera omisión del autor de la obra), el delito de plagio prevalecerá. Por lo demás, esta figura típica ostenta una pena mucho más grave (no menor de cuatro ni mayor de ocho años de pena privativa de la libertad, y noventa a ciento ochenta días-multa) que la reconocida para el delito contra la información sobre gestión de derechos (no mayor de dos años, y de diez a sesenta días-multa).

Una valoración final sobre este nuevo hecho punible, que conecta con los problemas interpretativos anteriormente advertidos, lleva a criticar la amplitud del tipo penal. Parece indiscutible que la necesidad de tutela de la información para la gestión de derechos «no sólo deriva de esa importancia de la información, sino también de la facilidad con la que la misma puede ser suprimida o alterada, sin que quienes accedan de una u otra forma a las copias alteradas o a copias de las mismas puedan percatarse de ello» (Bercovitz 2007, I28). No obstante, debemos apuntar que la protección de este tipo de información cobra más sentido en un contexto donde la distribución de las obras se lleva cada vez más a través de un entorno digital, en la red o empleando medios electrónicos. De ahí que en algunas legislaciones se hable más bien de gestión electrónica de derechos; cosa que pudo haber tomado en cuenta nuestro legislador, por lo menos para limitar o precisar el ámbito de lo penalmente relevante.

\section{III.4.3. Fabricación y comercialización de etiquetas}

El artículo 220-E del CP reprime conductas de fabricación, comercialización, distribución o almacenamiento de etiquetas o carátulas no auténticas para ser adheridas a un soporte material - al empaque- que contenga una obra protegida: audiovisual, de audio o programa de ordenador. Se trata de comportamientos similares a los previstos en el art. 223 a) del CP, los que fueron objeto de comentario en otro trabajo y al que, para mayores comentarios, me remito (Oré 2007, I59 y ss.). Cabe resaltar que el legislador incluye como modalidad típica una figura de mera posesión, a saber, el almacenamiento de etiquetas. No creemos necesario que las etiquetas estén ya colocadas o adheridas sobre los productos o empaques.

III.4.4. Manuales y licencias para programas de ordenador

El art. 220-F reprime a aquel que elabore, comercialice, distribuya almacene con fines comerciales manuales o licencias no auténticas para un programa de ordenador. Es de señalar que los programas de ordenador constituyen obras protegidas por el derecho de autor. De ahí que para la protección penal de los derechos sobre un programa de ordenador 
se pueda echar mano de las mismas figuras delictivas previstas para la infracción de los derechos de autor en las que estén involucradas otro tipo de obras protegidas. Por lo demás, el art. 69 del Dec. Leg. 822 señala que los programas de ordenador se protegen en los mismos términos que las obras literarias.

Es verdad que cabe distinguir entre la copia de seguridad de un programa de ordenador (permitida legalmente) y la copia privada para uso personal (que requiere autorización del titular). Claro que aún en este último caso -copia privada para uso personal de un programa de ordenador, sin autorización del titular- no cabe afirmar la concurrencia de un delito contra el derecho de autor, pues no concurre un afán de comercializar o distribuir la referida copia ${ }^{8}$.

El artículo comentado, como es fácil de ver, no reprime la reproducción de los programas, sino la elaboración, almacenamiento, comercialización y distribución de los manuales y licencias. Tratándose de licencias, podría haber un concurso aparente con el delito de falsificación de documentos privados, mas, por principio de especialidad, es de aplicación el delito ahora analizado.

\section{III.4.5. Protección de señales satelitales}

La Ley 29263 incorpora al catálogo penal una falta. En efecto, según el art. 444-A, se reprimirá, alternativamente, con prestación de servicios a la comunidad o multa, a aquel que reciba una señal de satélite portadora de un programa originariamente codificada, a sabiendas que fue decodificada sin la autorización del distribuidor legal de la señal. En cuanto al elemento subjetivo «a sabiendas», baste señalar que tiene la virtualidad (al menos teórica) de excluir la comisión a título de dolo eventual; por tanto, se exige dolo directo.

Normalmente se cuestiona la conveniencia político-criminal de sancionar el consumo personal, siendo que la persecución penal se dirige, sobre todo, contra actos de elaboración, producción, distribución o comercialización de mercancía ilícita (tráfico ilícito de drogas, falsificación de marcas, etc.). Quizás por ello se ha preferido configurar este comportamiento como una falta, y no como un delito. Cierto es que podría apreciarse alguna afinidad con el delito de hurto previsto en el segundo párrafo del art. I85 (hurto de energía eléctrica, gas, agua y cualquier otra energía o elemento que tenga valor económico, así como el espectro electromagnético). Con todo, la represión penal de esta figura venía exigida por el art. I6.8.I del APC, siendo que el Estado optó por cumplir el acuerdo considerando la recepción indebida de señales satelitales como una falta.

\section{III.5. La incautación y el comiso}

El legislador ha adicionado en el articulado referido a los delitos contra los Derechos de Autor normas que regulan medidas cautelares reales. Por estas entendemos la limitación de los derechos reales o patrimoniales del imputado a través de medidas concretas que recaen sobre elementos de prueba, o sobre los bienes del imputado y, eventualmente, del tercero civilmente responsable, para asegurar la actividad probatoria o las responsabilidades pecuniarias que pudieran derivar de una sentencia condenatoria. El art. 22I del Código Penal regula, de este modo, la incautación preventiva y el allanamiento, siendo que esta última está funcionalizada a los cometidos de aquélla.

${ }^{8}$ El principio de intervención mínima parecería desaconsejar la persecución penal de estos comportamientos. Como anota González Gómez (I998, 2II): «desde el punto de vista práctico, ni las autoridades judiciales, ni los (posibles) perjudicados han mostrado un particular interés en la persecución de copias ilícitas de software, si son para uso privado. Antes bien, se han centrado en la distribución profesional de aquéllas y en la denuncia de grandes empresas que utilizan, con fines comerciales, copias piratas de software». 
El allanamiento de inmuebles es una medida instrumental que, como señala Sánchez Velarde, tiene como finalidad la captura de la persona imputada de un hecho delictivo, y/o la incautación o secuestro de los bienes vinculados con los hechos que se investigan (Sánchez 2004, 837). La entrada en un inmueble en estas circunstancias supone una medida que afecta el derecho de la inviolabilidad del domicilio. Por esta razón, para la aplicación de la misma se requiere autorización judicial, no excluyéndose el empleo de la fuerza pública y hasta el descerraje, es decir, violentar la cerradura de una puerta.

En cuanto a la incautación, cabe afirmar que además de la función asegurativa de la prueba y de la reparación del daño, dicha medida cautelar puede asumir una función preventiva del delito. En este sentido, como dice García Luengo (2003, 628): «No hay duda que el perjudicado por la vulneración del derecho de marca tendrá interés no sólo en obtener la cesación de la misma, sino en que sea ordenada la retirada del tráfico económico de todo aquello que habiendo servido para la violación del derecho, pueda continuar produciendo efectos perjudiciales cuando son idóneos para ellos». De ahí que también pueda ser objeto de incautación los aparatos o medios utilizados para la comisión del delito.

Llama la atención que el legislador haya incluido en el articulado referido a los delitos contra el derecho de autor, normas procesales que regulan medidas como el allanamiento y la incautación. La influencia del Tratado de Libre Comercio firmado con los Estados Unidos es más que evidente. Basta echar una mirada al acápite 27 del art. I6.II del referido acuerdo comercial para corroborar ello9. Más allá de un discutido vacío legal, parece que lo que más ha primado para la inclusión de este tipo de normas en nuestro Código Penal han sido los compromisos asumidos por el Estado peruano en las diferentes mesas de negociación [para la suscripción de acuerdos comerciales] de las dos últimas décadas.

Sobre el comiso, se puede decir que tiene como fundamento la peligrosidad objetiva de algunos bienes o la no tolerancia al enriquecimiento injusto (García Cavero 2008, 745-755). Según el art. 221 CP, procede ante sentencias condenatorias. En estos casos, el material comisado [objetos de la infracción (ejemplares, materiales ilícitos) e instrumentos (aparatos y medios utilizados para la comisión del ilícito)] será destruido, salvo casos excepcionales. Tratándose de ejemplares de procedencia ilícita, no procederá «en ningún caso» la devolución de los mismos al encausado. Si entendemos bien, ni siquiera en aquellos casos en los que se expida una sentencia absolutoria se devolverá los bienes incautados de procedencia ilícita. Esto porque, nos imaginamos, dichos bienes son de comercio prohibido -en tanto vulneran un derecho exclusiva-.

Ahora bien, este último precepto, similar a otro que se prevé para el delito contra la propiedad industrial, puede plantear algunos problemas. Pongamos el siguiente ejemplo. Una firma extranjera otorga licencia a un empresario nacional para que, entre el i de enero de 2008 y el 3I de diciembre de 2010 , fabrique y distribuya a nivel nacional pantalones y casacas empleando su marca «X». Vencido el plazo, y luego de tres años de ventas exitosas, licenciante y licenciatario no llegan a un acuerdo para renovar la licencia. A pesar de esto, el empresario nacional no solo sigue comercializando las referidas prendas bajo la marca «X»,

\footnotetext{
9 «27. Específicamente, cada Parte dispondrá:

b) que sus autoridades judiciales estén facultadas para ordenar la incautación de mercancías presuntamente falsificadas o pirateadas, cualquier material relacionado e implementos utilizados en la comisión del delito, cualquier activo conectado a la actividad infractora y cualquier evidencia documental relevante al delito. Cada Parte dispondrá que los materiales sujetos a incautación de acuerdo con una orden judicial no requieren ser identificados individualmente a condición que se encuadren dentro de las categorías generales especificadas en la orden;

c) que sus autoridades judiciales estén facultadas para ordenar, entre otras medidas, el decomiso de cualquier activo conectado con la actividad infractora y ordenarán, salvo en casos excepcionales, el decomiso y destrucción de toda mercancía falsificada o pirateada, y, por lo menos con respecto a la piratería dolosa de derecho de autor o derechos conexos, ordenar el decomiso y destrucción de los materiales e implementos utilizados en la creación de las mercancías infractoras. Cada Parte dispondrá además que tal decomiso y destrucción no estarán sujetas a compensación alguna para el demandado».
} 
sino que también utiliza esta para comercializar camisas, polos y bolsos. Por si esto fuera poco, decide exportar todas estas prendas a Ecuador y Colombia. Formulada la denuncia penal, sin que denunciante y denunciado tengan realmente interés en llegar hasta las últimas instancias de un largo proceso judicial, el Fiscal aprecia la posibilidad de aplicar el principio de oportunidad [art. 2 CPP]. Imputado y agraviado no solo formalizan un acuerdo reparatorio, sino que deciden renovar la licencia. Consecuentemente, el Fiscal se abstiene de ejercitar la acción penal. En este contexto, el representante de la firma extranjera consiente para que se devuelva los ejemplares incautados al empresario nacional.

¿Es esto posible a pesar de que el legislador penal señala que en ningún caso procederá la devolución de los ejemplares ilícitos al encausado? Cierto es que, en este ejemplo, uno podría cuestionar que estemos ante un encausado, toda vez que no se llegó a etapa judicial, pero hay que tener en cuenta que el principio de oportunidad también puede plantearse ante el Juez, el mismo que puede disponer el sobreseimiento del caso. Con lo cual, si fuese el Juez quien dispone el sobreseimiento, seguiríamos ante el problema de qué hacer con los ejemplares incautados que en ningún caso puede devolverse al encausado.

Pues bien, estando a los fundamentos del comiso [peligrosidad objetiva de algunos bienes o la no tolerancia del enriquecimiento injusto] y, sobre todo, teniendo en cuenta que estamos ante la violación de un derecho de exclusiva -sin entrar ahora en el debate de si estamos ante un bien jurídico individual o supraindividual-, consideramos que en este caso específico es mejor -de manera similar a lo dispuesto por los arts. I97 y I97-A de la Ley sobre el Derecho de Autor ${ }^{\mathrm{IO}}$, y teniendo en cuenta lo previsto por el artículo 24I de la Decisión $486^{\text {II }}$ - dejar al titular del derecho de propiedad industrial afectado que disponga lo que crea más conveniente en cuanto al destino de los bienes ${ }^{\mathrm{I2}}$. Otra sería la solución, desde luego, si estuviésemos ante otro tipo de bienes [droga, mercancía de contrabando, productos pirotécnicos, etc.], casos en los cuales no procedería la devolución de los mismos al imputado.

\footnotetext{
Io Art. 197.- El cese de la actividad ilícita podrá comprender:

(...)

c. El retiro del comercio de los ejemplares ilícitos y su entrega al titular de los derechos vulnerados, en su caso, o su destrucción.

Art. 197-A.- Las autoridades judiciales procederán a destruir los bienes infractores del derecho de autor $y$ derechos conexos, a solicitud del titular del derecho, salvo circunstancia excepcional.

Asimismo, las autoridades judiciales estarán facultadas a ordenar que los materiales e implementos utilizados en la fabricación o creación de las mercancías infractoras sean prontamente destruidas sin compensación alguna y, en circunstancias excepcionales, se disponga su retiro de los canales comerciales a fin de prevenir futuras infracciones.
}

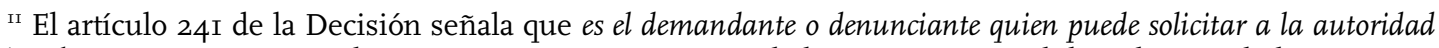
nacional competente que se ordenen, entre otras, una o más de las siguientes medidas: el retiro de los circuitos comerciales de los productos resultantes de la infracción, así como los materiales y medios que sirvieran para cometerlo [lit. c)]; la adjudicación en propiedad de los productos, materiales o medios referidos en el lit. c) [lit. e)]; la adopción de las medidas necesarias para evitar la continuación o repetición de la infracción, incluyendo la destrucción de los productos, materiales o medios referidos en el lit. c) [lit. f)].

I2 En todo caso, la entrega o puesta a disposición se podría hacer al agraviado, quien ya se encargaría de disponer el destino de los ejemplares. 


\section{Excurso: «El otro sendero»}

IV.I. Breve referencia de los hechos

Como es de público conocimiento, Enrique Ghersi y Mario Ghibellini reivindicaron su condición de coautores -conjuntamente con Hernando de Soto- del libro El Otro Sendero, pues, además de haber formado parte de la creación de la obra, desde las primeras ediciones figuraron en la carátula como colaboradores. Bien se recuerda que el Tribunal del Indecopi resolvió que El Otro Sendero es una obra colectiva y que se había afectado el derecho moral de paternidad al no haberse consignado como coautores en la edición del año 2005 a Enrique Ghersi y Mario Ghibellini; esto es, se quiso hacer pasar como una obra individual lo que en realidad era una obra colectiva ${ }^{\text {13 }}$.

No obstante ello, el Grupo Editorial Norma acaba de publicar una nueva edición del libro El Otro Sendero, en cuya carátula aparece como único autor Hernando de Soto. Sólo en los créditos de la cuarta página se consigna como coautores a Mario Ghibelini, Enrique Ghersi y el Instituto Libertad y Democracia.

IV.2. Sujeto activo del delito: ¿el autor de la obra?

Como sabemos, sujeto activo del delito es aquel que realiza el supuesto de hecho del tipo penal. En los delitos ahora analizados cabe destacar que, al menos en principio, no se exige una condición especial del agente para ser autor del delito, esto es, pueden ser cometidos por cualquier persona (delitos comunes). Cierto es que en el tipo básico del artículo 2I6 CP se alude al que actúa «estando autorizado para publicar una obra», con lo cual, se restringe, en este caso, el ámbito de posibles autores del delito.

No obstante, lo que ahora nos interesa determinar es un asunto más importante para determinar si los hechos denunciados tienen relevancia penal. Debemos preguntarnos: ¿puede el autor de la obra ser sujeto activo de un delito contra el derecho de autor sobre la misma obra?

Vayamos por partes. Hemos referido que el derecho de autor presenta un doble componente: uno moral que es, entre otras cosas, inalienable e irrenunciable (art. 2I LDA); y otro patrimonial, que sí es transferible, p. ej., mediante cesión inter vivos (art. 88 LDA).

Si el bien jurídico protegido por los delitos contra el derecho de autor abarca ambos aspectos, habrá supuestos delictivos en los que se afectará el aspecto moral del derecho de autor (p. ej. el de paternidad, en el delito de plagio o cuando se omite el nombre del autor) y otros en los que se afecta el aspecto patrimonial (p. ej. reproducción y distribución no autorizada de la obra).

Pongámonos ahora en el caso de que el titular de los derechos patrimoniales sobre una obra ya no sea el autor de la misma, sino un tercero: el autor, como titular original, cedió sus derechos de explotación económica a un tercero (cesionario).

Si se han cedido los derechos patrimoniales, los delitos que afecten el aspecto moral del derecho de autor se realizarán siempre en perjuicio del autor de la obra, pero los delitos que afecten los derechos patrimoniales lo serán ahora en perjuicio de quien ostente la titularidad de dichos derechos: el cesionario.

\footnotetext{
${ }^{13}$ vid. Resolución Nº723-2008/TPI-INDECOPI de 24 de marzo de 2008.
} 
De lo anterior, consideramos que es sostenible el argumento de que el autor de la obra podría eventualmente ser sujeto activo del delito en el caso de que haya cedido los derechos patrimoniales de la obra y que su conducta -la que se adecue al supuesto de hecho del tipo penal-suponga una afectación, justamente, de esa clase de derechos ${ }^{\mathrm{I4}}$.

En la misma línea, consideramos que el autor de la obra no puede ser sujeto activo del delito contra el derecho de autor cuando no haya cedido los derechos de la obra o, incluso habiéndolos cedido, cuando los comportamientos guarden relación con la posible vulneración de los derechos morales, de los cuales, evidentemente, él mismo continúa siendo titular.

IV.3. Coautor de la obra, ¿autor del delito?

Ahora bien, en el caso analizado se da una peculiaridad. Hernando de Soto es coautor de la obra. ¿Podría ser autor del delito? De los elementos con que contamos, pareciera que no. Por las siguientes razones.

I. Más allá de que en la nueva edición de El Otro Sendero no se incluya en la carátula el nombre de Enrique Ghersi y Mario Ghibelini, lo cierto es que no se les desconoce su condición de coautores, pues ello aparece, aunque de manera diminuta, en la cuarta página.

2. Hernando de Soto es coautor de la obra, con lo cual, no podría ser sujeto activo de un delito que afecte el derecho moral sobre aquella.

3. Si se afectó, como en este caso, los derechos morales de los demás coautores, es algo que debe ser ventilado en la vía extrapenal, en atención al principio de subsidiariedad y al carácter de ultima ratio del Derecho penal ${ }^{15}$.

4. Con relación a los derechos patrimoniales, es verdad que cualquier acto de explotación económica de la obra requería el común acuerdo de los coautores (artículo I4 LDA), sin embargo, ello no quita que Hernando de Soto, conjuntamente con Enrique Ghersi y Mario Ghibelini, sean titulares compartidos de los derechos patrimoniales sobre $E l$ Otro Sendero. Y así como, a nuestro entender, un copropietario no puede ser autor del delito de estelionato (vender como propio un bien ajeno: artículo I97 inc. 4 CP), consideramos que el coautor de la obra no puede ser autor del delito. Desde luego estamos ante una evidente violación del derecho de autor -en este caso en perjuicio de los coautores de la obra-, mas consideramos, al igual que en el apartado anterior, que esto debe ser solventado según las normas civiles y administrativas que la ley franquea.

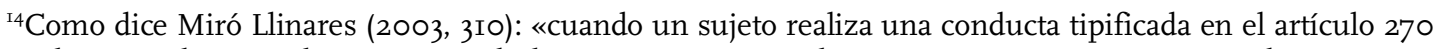
del Código Penal [español] con ánimo de lucro y en perjuicio de tercero, esto es, atenta contra los intereses patrimoniales de los titulares de los derechos de explotación exclusiva de propiedad intelectual (bien jurídico penal) de forma grave, debe ser castigado, con indiferencia de que, anteriormente, haya sido o no titular del bien jurídico e independientemente del resto de intereses (no protegidos por vía penal) que tenga respecto a la obra objeto de derechos». ABANTO VÁSQUEZ (2000, 284), en posición que no compartimos, va más lejos y excluye al autor de la obra como posible autor del delito: «si bien se protege también a los cesionarios de derechos autorales contra las acciones típicas allí descritas, esto sólo se hace en relación con terceros distintos del propio autor. En caso de que el autor cometa el ilícito, éste sólo deberá ser sancionado por las leyes extrapenales o, si emplea engaño y causa un perjuicio patrimonial al cesionario, por el tipo penal de 'estafa'».

${ }^{15}$ De la misma opinión, Miró Llinares (2003, 32I), quien sostiene «la explotación de la obra en su totalidad por parte de uno de los autores sin el permiso de los demás dará lugar a responsabilidad, si bien por la vía civil y no por la penal, en cuanto en este supuesto resultaría extraña la consideración de sujeto activo a uno de los titulares del bien jurídico protegido».
} 
IV.4. ¿Delito de desobediencia?

Por último, consideramos que tampoco concurre el delito de desobediencia, previsto en el artículo $368 \mathrm{CP}$ por cuanto este delito requiere, como elemento típico, la existencia de una orden impartida por un funcionario público en el ejercicio de sus funciones. En cuanto a este elemento, ya se ha señalado que no se trata de una simple citación, declaración, petición o notificación no conminatoria, sino de un mandato de carácter intimatorio que debe ser cumplida; se trata de una orden dirigida a un destinatario preciso al que se le conmina a hacer o dejar de hacer algo (Rojas 2003, 743).

Pues bien, la Resolución del Tribunal del Indecopi no contiene una orden o mandato dirigido a Hernando de Soto -salvo el pago de la multa y los costos del procedimiento. En este sentido, no existe un mandato expreso impartido por funcionario público que haya sido desobedecido.

\section{Bibliografía}

ABANTO VÁSQUEZ, M. (2000): Derecho Penal Económico. Parte Especial, Lima: Idemsa.

BAYLOS CORROZA, H. (I932): Tratado de Derecho Industrial. Propiedad industrial. Propiedad intelectual. Derecho de la competencia económica. Disciplina de la competencia desleal, $2^{\circ}$ ed, Madrid: Civitas.

BERCOVITZ, R. (2007): «La tutela de los derechos de Propiedad Intelectual en el ámbito digital», Anuario Andino de Derechos Intelectuales 3.

GARCÍA CAVERO, P (2008): Lecciones de Derecho Penal. Parte General, Lima: Grijley.

GARCÍA LUENGO, R. (2003): «Posibilidad de ejercitar acciones civiles y penales. Acciones civiles que puede ejercitar el titular de la marca», en A. Bercovitz (dir.) y J. A. García-Cruces (dir. adj.), Comentarios a la Ley de marcas, Navarra: Aranzadi, p. 613-63I.

GÓMEZ SEGADE, J. A. (200I): «La mundialización de la propiedad industrial y el Derecho de autor», en J. A. Gómez Segade, Tecnología y derecho. Estudios jurídicos del Prof. Dr. h. c. José Antonio Gómez Segade recopilados con ocasión de la conmemoración de los XXV años de cátedra, Madrid: Marcial Pons.

GONZÁLEZ GÓMEZ, A. (1998): El tipo básico de los delitos contra la propiedad intelectual. De la reforma de 1987 al Código penal de 1995, Madrid: Tecnos.

LIPSZYC, Delia (1993): Derecho de autor y derechos conexos, Buenos Aires: Zavalia.

MATIZ BULLA, C. (2002): «Delitos contra los derechos de autor en el nuevo Código penal (Ley 599 de 200I)», La Propiedad Inmaterial 5, p. 3-16.

MIRÓ LLINARES, F. (2003): La protección penal de la propiedad intelectual en la sociedad de la información, Madrid: Dykinson.

MIRÓ LLINARES, F. (2005): Internet $y$ delitos contra la propiedad intelectual. Madrid: Fundación Autor.

ORÉ SOSA, E. (2006): La protección penal de la marca en el Derecho español. Lima: Alternativas.

ORÉ SOSA, E. (2007): La infracción del derecho de marca, Lima: Palestra.

RANGEL MEDINA, D. (1998): Derecho Intelectual, México D. F.: McGraw-Hill.

RÍOS RUIZ, W. (2003): «Derechos de autor y derechos conexos en la televisión por satélite y televisión por cable - cable distribución. Señales portadoras de programas de satélite», La Propiedad Inmaterial, Universidad Externado de Colombia 6, p. 43-68.

RODRÍGUEZ GÓMEZ, C. (1996): Tesis doctoral: La tutela penal de las marcas $\gamma$ demás signos distintivos en el nuevo Código penal, Ignacio Berdugo (dir.), Universidad de Salamanca.

ROJAS VARGAS, F. (1997): Actos preparatorios, tentativa y consumación del delito, Lima: Grijley.

ROJAS VARGAS, F. (2003): Delitos contra la administración pública, Lima: Grijley.

SÁNCHEZ VELARDE, P. (2004): Manual de Derecho Procesal Penal, Lima: Idemsa. 